\title{
DESIGUALDAD Y POBREZA EXTREMA EN MUJERES INDÍGENAS MAYAS EN QUINTANA ROO, MÉXICO
}

\section{INEQUALITY AND EXTREME POVERTY IN MAYAN INDIGENOUS WOMEN IN QUINTANA ROO, MEXICO}

\author{
Miguel Angel Barrera-Rojas* \\ Alfredo Sánchez-Carballo** \\ Joel Ruíz-Sánchez ${ }^{* * *}$ \\ Natalia Ruiz-Guevara****
}

\section{RESUMEN}

Este trabajo presenta resultados de investigación en torno a las condiciones de pobreza que se suscitan en la Zona Maya de Quintana Roo, México, en el caso de las mujeres. Para el desarrollo metodológico, se replicó la variable Ingreso Corriente de la Encuesta Nacional de Ingreso y Gasto de los Hogares en México y se realizó trabajo de campo en localidades de dos municipios de esta zona. Se contrastaron los datos recabados contra tres indicadores de pobreza: Línea de pobreza extrema propuesta por Banco Mundial, la Línea de bienestar mínimo y la Línea de bienestar propuesta por el Consejo Nacional de Evaluación de la Política de Desarrollo Social. Finalmente, se presentan resultados donde se evidencia que existen condiciones de pobreza extrema en la población objeto de estudio y que las mujeres tienen ingresos muy por debajo y desiguales en comparación a los hombres, los cuales se encuentran soportados principalmente por dinero proveniente de programas de combate a la pobreza.

PALABRAS CLAVE: POBREZA * MUJERES INDÍGENAS * MÉXICO * POLÍTICA SOCIAL * POBREZA EXTREMA

\footnotetext{
* Universidad de Quintana Roo, México.

miguel.barrera@uqroo.edu.mx

** Universidad Autónoma de Ciudad Juárez, México. alscarballo@gmail.com

*** Universidad Autónoma del Estado de Morelos, México. jorsan30@hotmail.com

**** Centro Agronómico Tropical de Investigación y Enseñanza (CATIE), Costa Rica. natalia.ruiz@catie.ac.cr
} 


\begin{abstract}
This work presents research results about the conditions of poverty that arise in the Maya area of Quintana Roo, Mexico, particularly in women. For the methodological development, the variable Current Income of the National Household Income and Expenditure Survey in Mexico was replicated, field work was carried out in localities of two municipalities in the Maya area of Quintana Roo, Mexico and the data collected were contrasted against three indicators of poverty: extreme poverty line proposed by the World Bank, and the minimum well-being line and welfare line proposed by the National Council for the Evaluation of Social Development Policy. Finally, results are presented where it is evident that, in fact, there are conditions of extreme poverty in the population under study and that women have incomes far below and unequal to what men have, this, coupled with the fact that income of women are supported mainly by money from programs to combat poverty.
\end{abstract}

KEYWORDS: POVERTY * WOMEN * INDIGENOUS * MEXICO * SOCIAL POLICY * EXTREME POVERTY

\section{INTRODUCCIÓN: POLÍTICA SOCIAL Y COMBATE A LA POBREZA}

Autores como Martínez, Garmendia y Soto (2012) sostienen que la década de 1980 representó un parteaguas en la política económica mexicana, pues a partir de ese entonces las políticas de ideología neoliberal tomaron por avanzada la agenda nacional, derivando con ello a un abandono de la política de desarrollo social por parte del Estado, es decir, el combate a la pobreza se volvió una cuestión mayormente sustentada en el crecimiento económico, mas no así en el desarrollo económico. Estas nuevas políticas se derivaron de la liberalización de mercados en México y su supeditación a directrices neoliberales de Fondo Monetario Internacional (FMI) y el Banco Mundial (BM) (Kay, 2009; Martínez, Garmendia y Soto, 2012; Benítez, Rioja y Domínguez, 2016). Como parte de estas estrategias se llevó a cabo una drástica reducción del gasto público dirigido a salud, educación, cultura y ciencia, lo que derivó en incrementos de las tasas de desempleo, caída de las tasas de crecimiento, que incrementaron las tasas de pobreza en México, resultados que son evidentes en la actualidad (Escalante, 2015).

Como una estrategia para disminuir las crecientes tasas de pobreza, el Gobierno mexicano a nivel federal, durante la presidencia de
Ernesto Zedillo (1994-2000)1, diseñó una serie de políticas públicas de combate a la pobreza donde el componente principal fueron las transferencias monetarias condicionadas, que iniciaron en el año 1997 con el Programa de Educación, Salud y Alimentación (PROGRESA) ${ }^{2}$, el segundo en su tipo en América Latina. Este programa de transferencias logró beneficiar a

1 Cabe decir, que el programa PRospera tiene influencia de anteriores programas, tales como, el Programa de Inversiones Públicas para el Desarrollo Rural (PIDER) durante la década de 1960, programa Coordinación General del Plan Nacional de Zonas Deprimidas y Grupos Marginados (COMPLAMAR) y el Sistema Alimentario Mexicano (SAM) en el sexenio entre 1976 a 1982 y, finalmente, el Programa Nacional de Solidaridad (PRONASOL) fue puesto en actividad en 1988.

2 Durante el sexenio del presidente Zedillo se formuló el Programa de Educación, Salud y Alimentación (PROGRESA). Sus campos de acción se basaron en fortalecer: a) la educación, con el fin de garantizar la asistencia de los infantes en edad escolar, otorgando becas para que ninguno desertara del sistema de educación; b) en el eje de la salud, el programa tenía por objetivo disminuir las enfermedades $y$ mortalidad en niños menores de cinco años, mujeres embarazadas y en lactancia, $y$ c) alimentación, el objetivo era apoyar monetariamente a las familias beneficiarias con la finalidad de contribuir y mejorar la calidad del estado nutricional (Sánchez y Martínez, 2016, p. 36). 
6 millones de familias y fue replicado en varios países de la región.

Este tipo de estímulos, según diversas opiniones (Esquivel, 2015), no resuelven el problema de la pobreza, incluso, resultan perjudiciales porque la carga fiscal hacia las personas pobres se ha incrementado; por el contrario, para instancias como el Banco Interamericano de Desarrollo (BID, 2017) e incluso, el вм (2009), los programas de transferencias resultan la esperanza más confiable para reducir la brecha de pobreza. Después del PRospera, ha habido otros programas como el Programa de Desarrollo Humano Oportunidades (20002012), el cual conservó las directrices centrales del PROGRESA. El motivo de los cambios estaba influenciado por el interés de ampliar la cobertura de la política social, al implementar transferencias monetarias a las familias en condición de pobreza.

Siguiendo la misma lógica de las administraciones anteriores, para el año 2012, con el regreso del PRI al gobierno federal, se vuelven a ajustar las políticas sociales en materia de lucha contra la pobreza. Se modifica sustancialmente el programa Oportunidades para dar paso al programa PROSPERA. A principios de 2014, se daba a conocer oficialmente, por el presidente Enrique Peña Nieto, que PRosPera sería el nuevo programa dedicado a luchar contra la pobreza, en el cual se invirtieron, según datos oficiales, 73000 millones de pesos (Sánchez y Martínez, 2016).

Por su parte, la Comisión Económica para América Latina y el Caribe (CEPAL, 2013) analizó específicamente el efecto de los programas de transferencias condicionadas para mujeres en México y otros países de Latinoamérica y señaló en un informe que, si bien, estas han constituido un hito innovador en las políticas públicas para abordar de manera directa la pobreza y pobreza extrema, estas medidas tienen varias aristas tanto positivas como negativas en lo referente a sus efectos sobre la equidad de género. Además, se evidencia que las mujeres no son las beneficiarias reales sino operativas de los programas de transferencias en sus diferentes versiones y etapas (los beneficiarios finales serían sus hijos e hijas). Por este motivo, puede afirmarse que con estas estrategias de los programas se refuerzan los roles de género para cumplir con las condiciones de la transferencia monetaria (mujer cuidadora que vela por la asistencia de hijos a la escuela y a los programas de salud), la imposición de cargas adicionales para las mujeres (gestión de certificados, asistencia a charlas, etc.), la no contribución a su inserción en el mercado laboral, etc.

Según Rodríguez (2011) y cEPAL (2013), los programas de transferencias condicionadas (PROSPERA, Oportunidades, PROGRESA, para el caso de México) perpetúan una organización del cuidado de las familias $y$, por ende, de la sociedad basada en el trabajo no remunerado de las mujeres, que es una de las tantas causas de la desigualdad económica de género, según el tercer informe del Observatorio de Igualdad de Género de América Latina y el Caribe (OIG) Los bonos en la mira: aporte y carga para las mujeres $^{3}$ (CEPAL, 2012). Este informe señala que estos programas se orientan a las mujeres (que ocupan la posición de "enlace" entre el programa y los beneficiarios) ya que en países donde operan, como México, conceden ingresos monetarios para salud $y$ educación de los infantes a través de la contraprestación de asistencia por parte de las madres de familia.

México, como país miembro de la Organización de las Naciones Unidas (ONU), se comprometió en el año 2000 a cumplir los Objetivos del Milenio, entre los que destaca el número "1.A. Reducir a la mitad, entre 1990 y 2015, la proporción de personas con ingresos inferiores a 1 dólar por día” (ONU, 2000). Esta medida de 1 dólar norteamericano por día surgió en 1991, "con el fin de ecualizar el poder adquisitivo de los ingresos, la moneda local se expresa en

$3 \quad$ Según la propia CePAL (2013, p.7): "Este informe del Observatorio de Igualdad de Género de América Latina y el Caribe (OIG) se centra la mirada en el análisis de los indicadores de autonomía física, económica y en la toma de decisiones, cuyo telón de fondo es la agenda regional generada por los consensos ratificados en la XI Conferencia Regional sobre la Mujer de América Latina y el Caribe, concordantes con la Plataforma de Acción de la Cuarta Conferencia Mundial sobre la Mujer (Beijing, 1995)". 
términos de su equivalencia de poder adquisitivo mediante el uso de dólares de "paridad del poder adquisitivo" (PPA)".

De acuerdo con un informe de la CEPAL sobre indicadores de pobreza y pobreza extrema para América Latina:

En 1991 se estimó una línea internacional de pobreza equivalente a 1 us\$ PPA diario a precios de 1985, razón por lo cual la línea se dio a conocer como "1 dólar al día”. En el 2000 la línea fue recalculada a precios de 1993, y se fijó en 1,08 US\$ PPA. Posteriormente, sobre la base de los nuevos índices de PPA generados por el Programa de Comparación Internacional de 2005, se determinó un nuevo umbral, de 1,25 US\$ PPA diario" (CEPAL, 2016, s.p.).

Este nuevo umbral que es considerado de pobreza extrema en las metas del Objetivo de Desarrollo Sostenible (oDs) nro.1 de la Agenda 2030 de la onU, México también lo ha suscrito, en reemplazo de los Objetivos de Desarrollo del Milenio. De acuerdo con las metas definidas para este objetivo, esto significa que para el año 2030, el país se ha comprometido a reducir a cero la cifra de 9.4 millones de personas en situación de pobreza extrema ${ }^{4}$ y a la mitad el número de 53.4 millones de personas en situación de pobreza $^{5}$ (CONEval, 2016). La reducción de la

4 Según el coneval (2016, s/p), en el glosario metodológico establece que la "pobreza extrema debe entenderse cuando una persona tiene tres o más carencias, de seis posibles, dentro del Índice de Privación Social y que, además, se encuentra por debajo de la línea de bienestar mínimo. Las personas en esta situación disponen de un ingreso tan bajo que, aun si lo dedicase por completo a la adquisición de alimentos, no podría adquirir los nutrientes necesarios para tener una vida sana". Para mayor información sobre dicho glosario, consultar https://www.coneval.org.mx/Medicion/ Paginas/Glosario.aspx

A diferencia de pobreza extrema, cuando el conEVAL (2016, s.p.) se refiere a pobreza alude a la situación de una persona cuando "tiene al menos una carencia social (en los seis indicadores de rezago educativo, acceso a servicios de salud, acceso a la seguridad social, calidad y espacios de pobreza (ya sea enfocada de manera unidimensional o multidimensional) no es el único factor que se debe enfrentar con la implementación de programas de transferencias monetarias. En los últimos años, se ha considerado que lograr una sociedad justa sostenible $y$ equitativa es el fin último del desarrollo, para lo cual es necesario entender y abarcar las diferencias en la calidad de vida $y$ pobreza entre los distintos grupos de la sociedad. CEPAL (2016), abarca la desigualdad teniendo como eje central los aspectos socioeconómicos, sobre todo en las diferencias de ingresos (medidos a través del índice de Gini).

\section{DESIGUALDAD EN LA ZONA MAYA}

El tema de la desigualdad en México y América Latina no es nuevo. De hecho, México es una de las economías más desiguales del planeta. Dentro de la literatura académica que se revisó vale la pena mencionar el trabajo de Ortíz y Cummins (2012), quienes en un extenso texto que elaboraron para la UNICEF, realizan un robusto análisis sobre desigualdad a partir de los datos de pobreza del Banco Mundial y exhortan en las conclusiones a generar mecanismos de amortiguación y recuperación económica especialmente para las regiones y naciones menos favorecidas tras las crisis económicas del 2007 y 2008. Por su parte, Cortés (2002) quien analiza las condiciones de desigualdad y pobreza en México, dando como elemento de análisis la crisis de 1994, tras la cual, evidentemente disminuyó la desigualdad, pero la pobreza de tornó más acentuada. En otro documento, Cortés (2013) analiza la desigualdad en México durante los últimos 50 años, diviéndolos en tres periodos: la del Estado benefactor, la de transición al neoliberalismo y la etapa neoliberal. El autor resalta la transformación del coeficiente de Gini en el periodo de estudio y cómo la desigualdad fue factor determinante

\footnotetext{
la vivienda, servicios básicos en la vivienda y acceso a la alimentación) y su ingreso es insuficiente para adquirir los bienes y servicios que requiere para satisfacer sus necesidades alimentarias y no alimentarias". Para más información sobre dicho glosario, consultar https://www.coneval.org.mx/ Medicion/Paginas/Glosario.aspx
} 
para el tipo de política económica que se implementó en cada época.

En lo que respecta a estudios sobre pobreza en mujeres, hay dos trabajos que se consideran valiosos. El primero es un cuaderno de trabajo del Instituto Nacional de las Mujeres (2009) donde se desagregan indicadores de medición de pobreza extrema y alimentaria en mujeres mexicanas. Para ello recurren a la metodología de línea de pobreza y al coeficiente de Engels. El otro trabajo es el de ONU Mujeres (2016) quienes analizan desde la perspectiva normativa e institucional la situación de pobreza de las mujeres en el mundo. En ese documento se detalla en términos de libertades $y$ capacidades que son las mujeres quienes están en situaciones más precarias, $y$ hace falta que se genere mayor información sobre su situación en derechos económicos, políticos y sociales.

De hecho, la gran mayoría de los trabajos académicos disponibles, si bien analizan con rigurosidad a la desigualdad y la pobreza en México, la gran mayoría lo hace desde una perspectiva nacional. Son escasos aquellos donde el énfasis en el análisis se hace para mujeres indígenas, por ejemplo, el trabajo de Bello y Rangel (2002) o el de Trivelli (2008) quienes analizan condiciones de desigualdad y pobreza en América Latina $y$ el Caribe en poblaciones rurales e indígenas. De ahí que este trabajo sea relevante, pues analiza con datos recolectados en campo la situación que viven las mujeres de la etnia Maya yucateca en Quintana Roo, México.

De acuerdo con los resultados obtenidos con el índice de Gini, en México, en los últimos 8 años, se había mantenido con poca o nula variación (alrededor de 0.52). Este análisis, se basa en las diferencias de ingresos, pero estudia también la influencia de varios factores, como son el género, residencia, etnia y nivel de educación. Es así como determina que las mujeres ocupan prioritariamente los quintiles de menores ingresos de la población y relaciona este hecho con la alta carga de trabajo doméstico no remunerada que tiene un valor económico invisible y que las limita para acceder a oportunidades de capacitación y empleo. Al mismo tiempo, los salarios promedio de las mujeres, en caso de que sean empleadas, suelen ser hasta un $89 \%$ inferiores a los de los hombres, enfrentándose así a diversos obstáculos (menos horas trabajadas, segregación en tipo de ocupaciones, "techo de cristal", por mencionar algunas). Dentro de estas desigualdades de género, hay factores que las acentúan, tales como un menor grado de formación académica, la presencia de niños menores en el hogar (que requieren mayor atención y cuidado) y la pertenencia previa a un estrato socioeconómico pobre.

Otro tipo de desigualdad analizada por CEPAL es la denominada "funcional", determinando que en América Latina y México hay una tendencia clara a retribuir en valor económico mucho más al capital (inversiones) que al trabajo (empleo), lo cual se determina por la participación de los salarios en el Producto Interno Bruto (PIB). En este mismo documento, se presentan los resultados de un estudio realizado en México, el cual revela que dos terceras partes de los activos físicos y financieros del país están en manos del 10\% de las familias, en tanto que el $1 \%$ de las familias concentran más de un tercio, por lo que la desigualdad en la posesión de activos alcanza la cifra alarmante de 0.93 en el coeficiente de Gini. En otras ediciones de "Panorama Social de América Latina", de la CEPAL (2014 y 2015) exhiben la relación de la desigualdad con factores como la residencia (urbano, urbano-marginal o rural, en el que se excluye a las personas pobres de los circuitos de valor económico), etnia o condición de migrante (discriminación).

Es por ello que el nro. 10 del oDs propone como meta para el año 2030 "reducir la desigualdad en los países y entre ellos", fijando como primer objetivo lograr y mantener sostenidamente el incremento de los ingresos del $40 \%$ de la población más pobre, además de generar un contexto de inclusión en lo referido a políticas, oportunidades, representación, reglamentación, entre otros. Para este objetivo, en el país se han fijado tres estrategias basadas en aspectos económicos:

$\diamond \quad$ “ (..) Aplicar el principio del trato especial y diferenciado para los países en desarrollo, en particular los países menos adelantados, de conformidad con 
los acuerdos de la Organización Mundial del Comercio,

$\diamond \quad$ Alentar la asistencia oficial para el desarrollo y las corrientes financieras, incluida la inversión extranjera directa, para los Estados con mayores necesidades, en consonancia con sus planes y programas nacionales.

$\diamond \quad$ Reducir a menos del 3\% los costos de transacción de las remesas de los migrantes y eliminar los canales de envío de remesas con un costo superior al 5\%" (ONU México, 2015, s.p.).

En estrecha relación con estas metas, para el cumplimiento del nro. 5 (Lograr la igualdad de género y empoderar a todas las mujeres y las niñas), México ha propuesto las siguientes estrategias:

a) Emprender reformas que otorguen a la mujer el derecho en condiciones de igualdad a los recursos económicos, así como el acceso a la propiedad $y$ al control de la tierra $y$ otros bienes, los servicios financieros, la herencia y los recursos naturales, de conformidad con las leyes nacionales, b) Mejorar el uso de la tecnología instrumental, en particular la tecnología de la información y las comunicaciones, para promover el empoderamiento de la mujer y c) Adoptar $y$ fortalecer políticas acertadas y leyes aplicables para promover la igualdad de género y el empoderamiento de todas las mujeres $y$ las niñas a todos los niveles (onU México, 2015, s.p.).

Como se observa, a diferencia de las metas para el oDs nro. 1, no se ha cuantificado la cantidad de personas que se verían beneficiadas por las acciones orientadas a cumplir los ODS nro. 5 y nro. 10. La desigualdad económica en la sociedad es uno de los temas que más interesa a los estudiosos de las ciencias sociales, ya que de este fenómeno se desprenden problemas más complejos como la pobreza, la marginación e incluso, la violencia (Yarrington, 2013).
En la literatura existente sobre la pobreza extrema, el énfasis se concentra en la distribución del ingreso, pues determina si el individuo está encima o debajo del indicador en cuestión. Al respecto, Feres y Mancero (2001) establecieron para la medición de la distribución del ingreso, una división sobre las metodologías muy práctica y que se ajusta a la realidad latinoamericana. En su estudio, los autores plantean la idea de diferenciar los indicadores de bienestar, al respecto aseveran que "la identificación de los pobres implica realizar una comparación entre distintos niveles de bienestar. Por tanto, se debe elegir una variable cuantificable que actúe como indicador del nivel de bienestar de las personas" (Feres y Mancero, 2011, p.50). Por lo anterior, es que el Ingreso Total es la variable que se ha elegido como cuantificable y las líneas de pobreza propuestas por el вм y el Consejo Nacional de Evaluación de la Política de Desarrollo Social (Coneval) como método de contraste. Este método constituirá un auxiliar teórico metodológico fundamental, ya que el ingreso corriente per cápita se contrastará contra la línea de bienestar y bienestar mínimo que el conEval establece para México y contra las líneas de pobreza extrema del BM.

Es importante señalar que el origen de este método se remonta a 1880 cuando en una conferencia de la Royal Statistical Society se propuso segmentar a la población por líneas en términos de su ingreso, es decir, las familias que cumplieran con cierta cantidad de ingreso $y$ de nivel de empleo se encontraban "por encima de la línea de pobreza" (Gillie, 2008, p. 715). $\mathrm{Su}$ uso académico ha sido de tal tamaño que incluso organismos internacionales como el BM lo utilizó en varios informes (2004 y 2013) para definir como pobreza extrema a la población que vive al día con menos de $\$ 1.25$ y de $\$ 2.50$ dólares americanos de paridad de poder adquisitivo (PPA).

Actualmente, el propio CONEVAL se encarga de medir la pobreza en México de manera multidimensional. Esta institución considera seis carencias sociales: educación, salud, seguridad social, vivienda, servicios básicos y alimentación. Al mismo tiempo, esta metodología considera, 
al menos, los siguientes 8 indicadores en su medición de la pobreza: "1) Ingreso corriente per cápita, 2) Rezago educativo promedio en el hogar, 3) Acceso a los servicios de Salud, 4) Acceso a seguridad social, 5) Calidad y espacios de la vivienda, 6) Acceso a los servicios básicos en la vivienda, 7) Acceso a la alimentación y, 8) Grado de cohesión social" (CONEval, 2010, p. 5).

En lo que se refiere al ingreso corriente, el CONEval (2010 y 2014) señala que "se identifica a la población en situación de pobreza como aquella que padece al menos una carencia social y tiene un ingreso inferior al valor de la Línea de Bienestar" (p.8). De ahí que se haya elegido utilizar estas líneas propuestas para el caso de las comunidades de estudio de esta tesis doctoral. Para el caso concreto de México, según el coneval (2010): "En México se han empleado metodologías similares, pero con valores de líneas distintos, los cuales resultan de la construcción de canastas con diferentes composiciones" (p.8).

Estas mediciones de la pobreza en México han arrojado dos realidades muy distantes: el México urbano y el México rural (Cornelius y Myhre, 1998). Esta última realidad también se puede dividir en dos: lo rural y lo rural indígena (Delgado, 1999). Es precisamente en esta última realidad donde se sitúa el presente texto, en la zona indígena Maya de Quintana Roo, esta zona se compone principalmente de los municipios de Felipe Carrillo Puerto y José María Morelos. Ambos municipios tienen vocación productiva que tiende al campesinado y en menor medida a la prestación de servicios de turismo alternativo y comercio. Dicha vocación provee un contexto donde el desempleo es una constante, las opciones laborales son pocas, la descampesinización es latente y la ausencia de servicios básicos es evidente (Ramírez e Ibarra, 2015; Gaxiola y Castro, 2017).

Así, el objetivo de este trabajo es hacer un estudio comparativo del ingreso corriente entre mujeres $y$ hombres de dos municipios de Quintana Roo para evidenciar, con el tipo de análisis propuesto, la pobreza extrema que está presente en mayor cantidad en las mujeres que en los hombres. Para alcanzar el objetivo anterior, se han delimitado dos zonas de estudio: los municipios de Felipe Carrillo Puerto y José María Morelos en el Estado de Quintana Roo. En dichos municipios, se llevó a cabo el trabajo en campo en las localidades de José María Morelos, Dos Aguadas, El Naranjal, San Carlos, San Diego, Dziuché, Felipe Carrillo Puerto y Noh-Bec (mapa 1). 
MAPA 1

REGIÓN Y LOCALIDADES DE ESTUDIO

MÉXICO

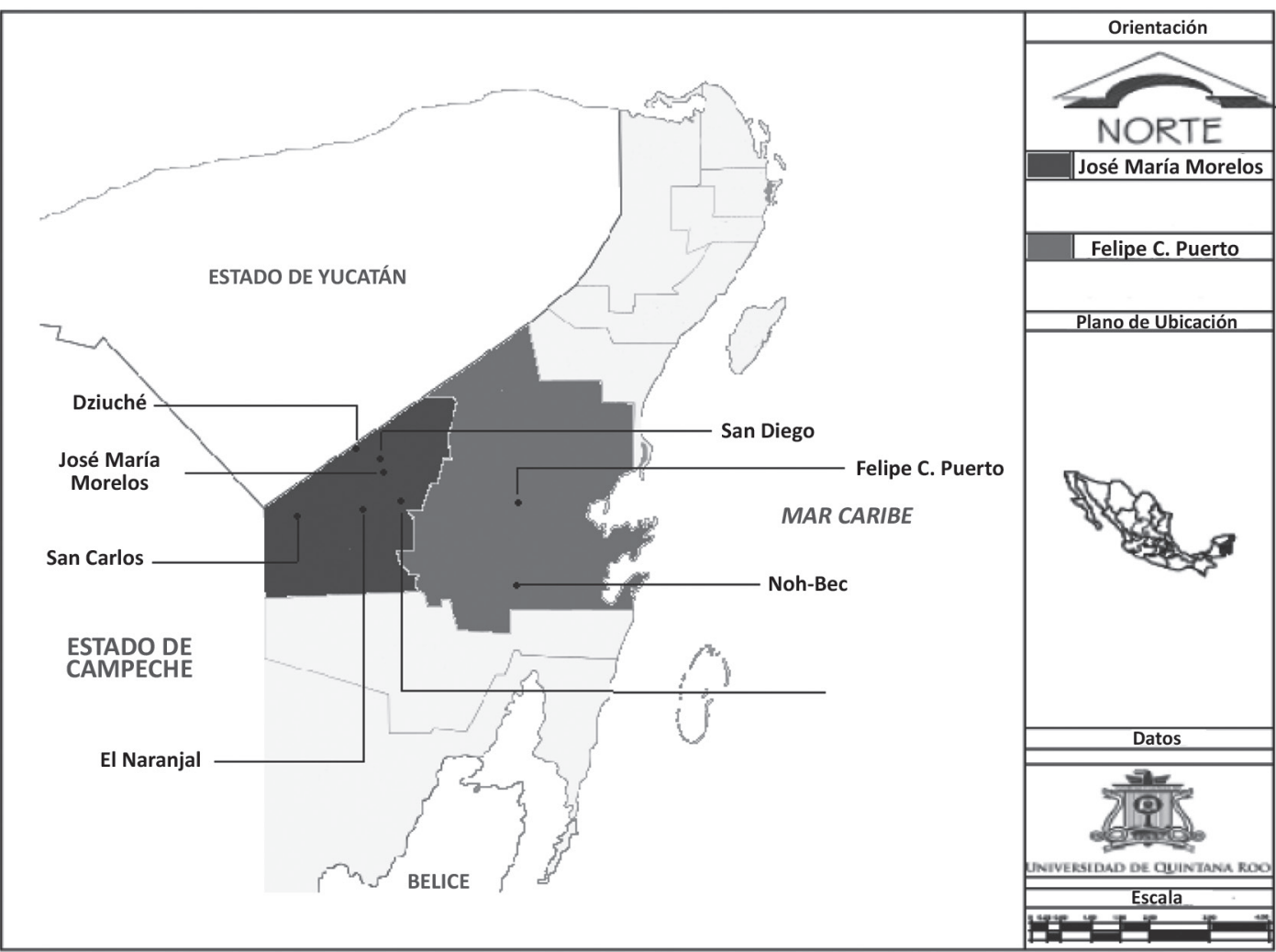

Fuente: Elaboración propia.

\section{METODOLOGÍA}

Para dar respuesta al objetivo de este trabajo, se construyó la variable Ingreso Corriente (Ic) de la misma manera en que el Instituto Nacional de Estadística, Geografía e Informática (INEGI) lo hace para la Encuesta Nacional de Ingreso y Gasto de los Hogares (ENIGH). Dicho IC "Se forma por las entradas monetarias y no monetarias que satisfacen estos tres criterios: Regularidad, Disponibilidad, Patrimonio" (INEGI, 2013, p.1). Este Ic está dividido en 5 partes: 1) Ingreso por la vía del trabajo (IT); 2) Renta de la propiedad (IR); 3) Transferencias (TR); 4) Estimación del alquiler de la vivienda (Av); y 5) Otros ingresos corrientes (OI):

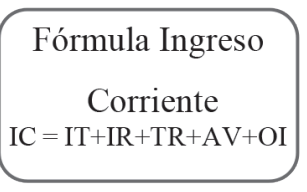

Para IT se consideran todos aquellos ingresos que sean por medio del trabajo subordinado, trabajo independiente $u$ otras formas de empleo. IR representa dos tipos de ingresos, el primero es la participación monetaria que los integrantes del hogar tienen proveniente de cooperativas y sociedades de empresas; la segunda es como ingreso por el arrendamiento de activos fijos dentro y fuera del país, así como, los dividendos de la posesión de activos financieros y cuentas de ahorro. 
El rubro de TR es definido por INEGI (2013) como "las entradas monetarias recibidas por los integrantes del hogar y por las cuales el proveedor o donante no demanda retribución de ninguna naturaleza" (p. 4). En lo que refiere a AV, se pregunta por el monto que se paga por el alquiler de la vivienda o bien una estimación, en caso de vivir en casa propia, de lo que se pagaría por una vivienda en alquiler con las mismas características de la que se tiene. on representa ingresos que estén fuera de los rubros anteriormente descritos.

La muestra que se calculó fue igual a 140 hogares, sin embargo, la información recabada acumuló un total de 196 hogares, los cuales agruparon un total de 911 individuos, $y$ se determinó de la siguiente manera:

$$
n=z_{\propto}^{2}\left(\frac{N^{*} p^{*} q}{i^{2}(N-1)+z_{\propto}^{2 *} p^{*} q}\right)
$$

Donde

$\mathrm{N} \rightarrow$ tamaño de la población $\left(10,182^{6}\right)$

$\mathrm{z} \rightarrow$ valor de la distribución de Gauss $=2.38$ para $98 \%$ de intervalo de confianza

$\mathrm{p} \rightarrow$ prevalencia esperada del parámetro a evaluar (0.5)

$q \rightarrow 1-p=0$.

$\mathrm{i} \rightarrow$ error que se prevé cometer $(0.10)$

Para la afirmación anterior se utilizó la Penn World Table para determinar que el tipo de cambio del dólar a precios de 2005 es de $\$ 10,897^{7}$.
YEAR MEXICO/EXCHANGE RATE

(US=1)
NATIONAL CURRENCY

PURCHASING POWER PARITY

6 De acuerdo al censo del INEGI (2010), el número de hogares en las localidades de estudio es El Naranjal (135), San Carlos (27), San Diego (120), Dziuche (702), José María Morelos (2626), Dos Aguadas (40), Noh-Bec (505) y Felipe Carrillo Puerto (6027).

$7 \quad$ Si se considerara el tipo de cambio promedio de marzo de $2016(\$ 18,50)$, entonces, el porcentaje de hogares que viven con menos de 1,25 dólares americanos diarios sería del 38\%. 


\section{RESULTADOS Y DISCUSIÓN}

El trabajo de campo que se realizó arrojó una muestra de 911 personas, de las cuales 462 fueron hombres $(50,71 \%)$ y 449 mujeres (49,28\%). De estas, 289 personas $(31,72 \%)$ reportaron ser mayaparlantes natos, mientras que 549 personas $(60,26 \%)$ indicaron que su lengua materna es el castellano, y finalmente, un dato que llamó la atención fue que 73 personas $(8,01 \%)$ tienen por lengua materna la Maya Tzotzil, que es una lengua típicamente hablada en Guatemala y Chiapas y no dominante en la zona del estudio realizado. El tamaño medio del hogar de la muestra es de 4.3 miembros.

En lo referente a la educación, el promedio de años que la muestra asistió a la escuela es de 6,64 (en los hombres es de 6,54 y de las mujeres es de 6,70), es decir, tienen la primaria concluida e iniciado el primero de secundaria.

En lo que refiere al Ic, en la tabla 1, se muestra la estadística básica de dicha variable, además de observar que el dato con ingreso más alto corresponde a un hombre y es superior al millón de pesos anual (56,320 dólares americanos), el ingreso máximo reportado por una mujer es de casi una cuarta parte del dato máximo general. Otra peculiaridad de estos datos radica en que los hombres con ingreso igual a cero son 135 (29,22\% del total de los hombres), mientras que las mujeres suman 190 (42,31\% del total de las mujeres). De ahí la insistencia de centrar este artículo a la pobreza extrema entre las mujeres. De igual modo, en la tabla 2 se puede observar que el número de mujeres por debajo de las tres líneas de pobreza evaluadas es más alto en relación con los hombres, especialmente en la línea de pobreza extrema del вм, que indica que el 53,22\% de las mujeres están en esta condición, mientras que en los hombres el porcentaje es 49,33\%, situación que también es preocupante, pues en ambos casos promedian el 51\% con ingresos por debajo de un dólar y medio al día.

TABLA 1

ESTADÍSTICA BÁSICA DEL INGRESO CORRIENTE (PESOS MEXICANOS) 2016

\begin{tabular}{l|c|cc}
\hline & TOTAL & HOMBRES & MUJERES \\
\hline Media & $\$ 19031,13$ & $\$ 25004,53$ & $\$ 12877,42$ \\
Mediana & $\$ 4800,00$ & $\$ 10000,00$ & $\$ 4500,00$ \\
Moda & $\$ 0$ & $\$ 0$ & $\$ 0$ \\
Máximo & $\$ 1080000,00$ & $\$ 1080000,00$ & $\$ 255000,00$ \\
Mínimo & $\$ 0$ & $\$ 0$ & $\$ 0$ \\
Desviación estándar & $\$ 58319,12$ & $\$ 62011,79$ & $\$ 26272,18$ \\
\hline
\end{tabular}

Fuente: Elaboración propia con datos recolectados en campo. 
TABLA 2

INCIDENCIA DE POBREZA POR GÉNERO EN LAS LOCALIDADES DE ESTUDIO 2016

\begin{tabular}{l|lc}
\hline HOMBRES & TOTAL DATOS & 462 \\
\cline { 2 - 3 } & Debajo de la línea de BM & 259 \\
& Debajo de la línea de B & 313 \\
& Debajo de la línea de pobreza extrema & 228 \\
\hline MUJERES & TOTAL DATOS & 449 \\
\cline { 2 - 3 } & Debajo de la línea de BM & 344 \\
& Debajo de la línea de B & 239 \\
\hline
\end{tabular}

Fuente: Elaboración propia con datos recolectados en campo.

En el gráfico 1, se observa el ingreso de toda la muestra, resaltando tanto el outlayer máximo, cuyo IC es superior al millón de pesos anuales, como los outlayer mínimos que están con IC igual a cero y una altísima concentración de ingresos anuales inferiores a los $\$ 75000,00$ pesos.

GRÁFICO 1

INGRESO CORRIENTE PARA LA MUESTRA 2016

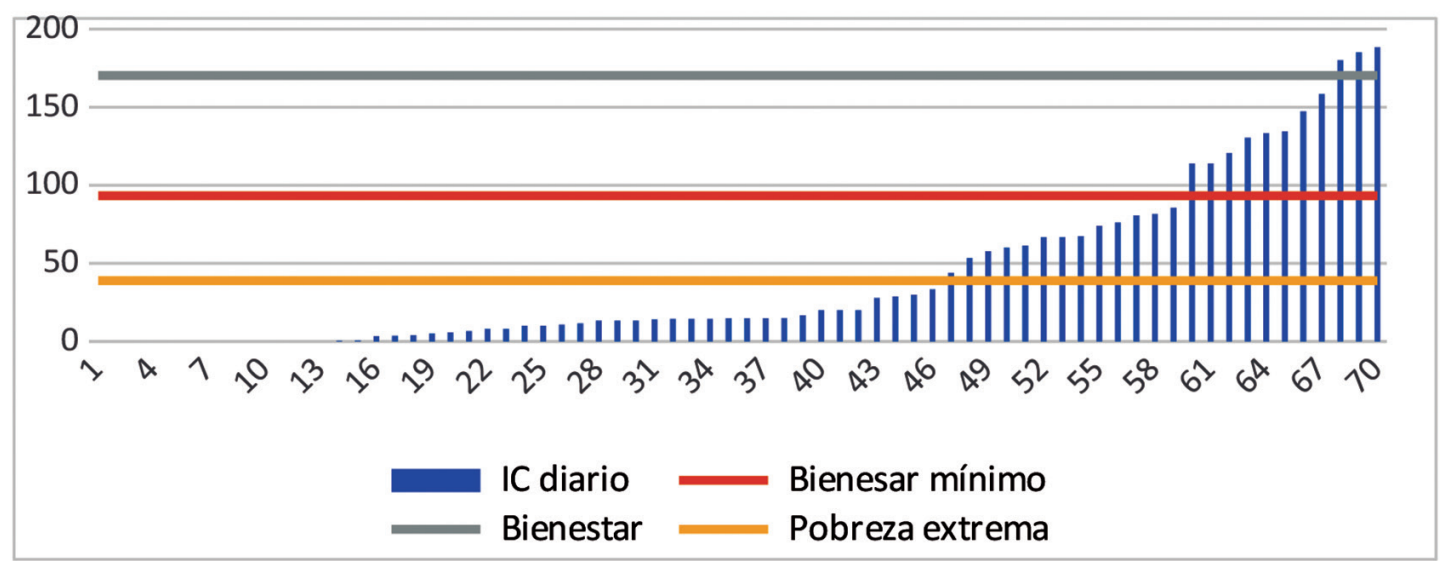

Fuente: Elaboración propia con datos recolectados en campo. 
En el gráfico 2 se establece una comparación entre los ingresos de hombres y mujeres por separado, mostrando claramente la desigualdad $y$ la vulnerabilidad que sufren las mujeres, pues son las que mayor incidencia tienen de Ic igual a cero y además, la mujer que mayor ingreso registra no es ni cercana al hombre con mayor ingreso. De ahí que el énfasis de este trabajo por mostrar y esbozar la realidad económica que viven las mujeres indígenas de Quintana Roo, México.

\section{GRÁFICO 2 \\ INGRESO ENTRE HOMBRES Y MUJERES ${ }^{8}$ \\ 2016}

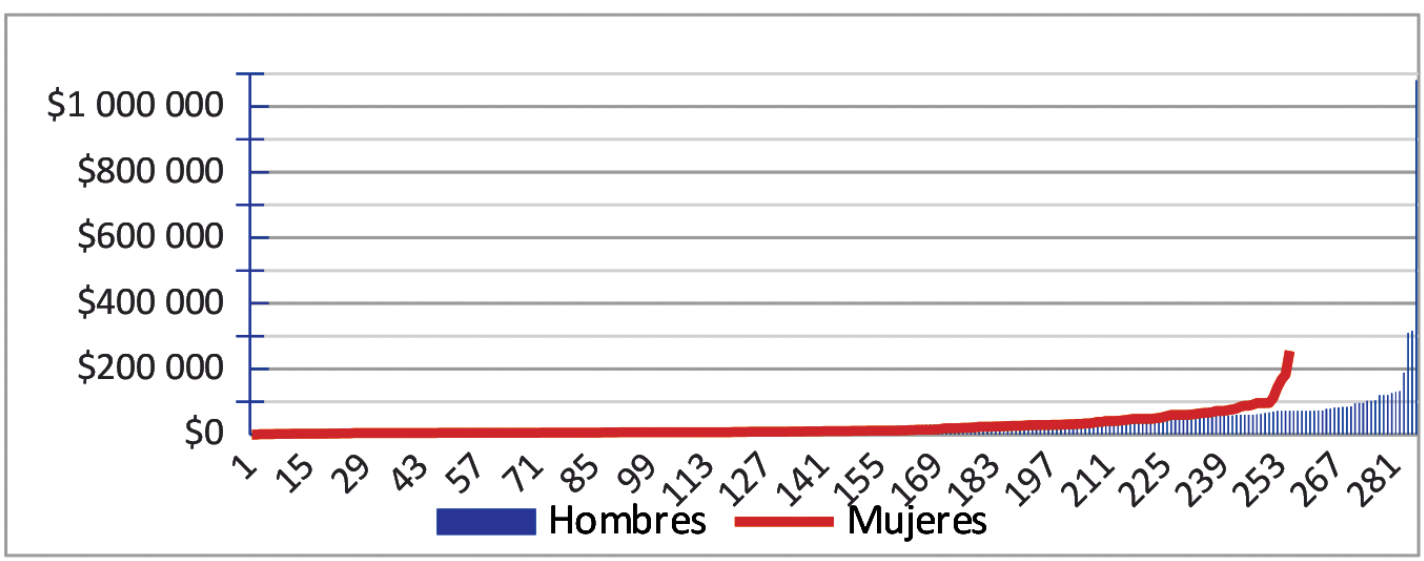

Fuente: Elaboración propia con datos recolectados en campo.

En el gráfico 3, se observa que el eje de las ordenadas está dividido en duodeciles, estos se calcularon a razón de que el coneval establece que $\$ 1787,1$ es ingreso suficiente para superar la línea de bienestar, así, el ingreso anualizado debe ser $\$ 21444,00$, mismo que se utilizó como ancho de clase para esta gráfica. Pues bien, en la mencionada gráfica se observa que en ingreso iguala cero y en el primer decil de ingreso más bajo la incidencia de casos de mujeres es más alta, mientras que en los ingresos medios y altos la incidencia de casos de mujeres es más baja.

8 En este gráfico se eliminaron todos aquellos datos con ingreso igual a cero pesos (176 hombres y 192 mujeres),para una mayor claridad de la persona lectora. 


\section{GRÁFICO 3 \\ INGRESO CORRIENTE POR ACUMULADO ENTRE HOMBRES Y MUJERES

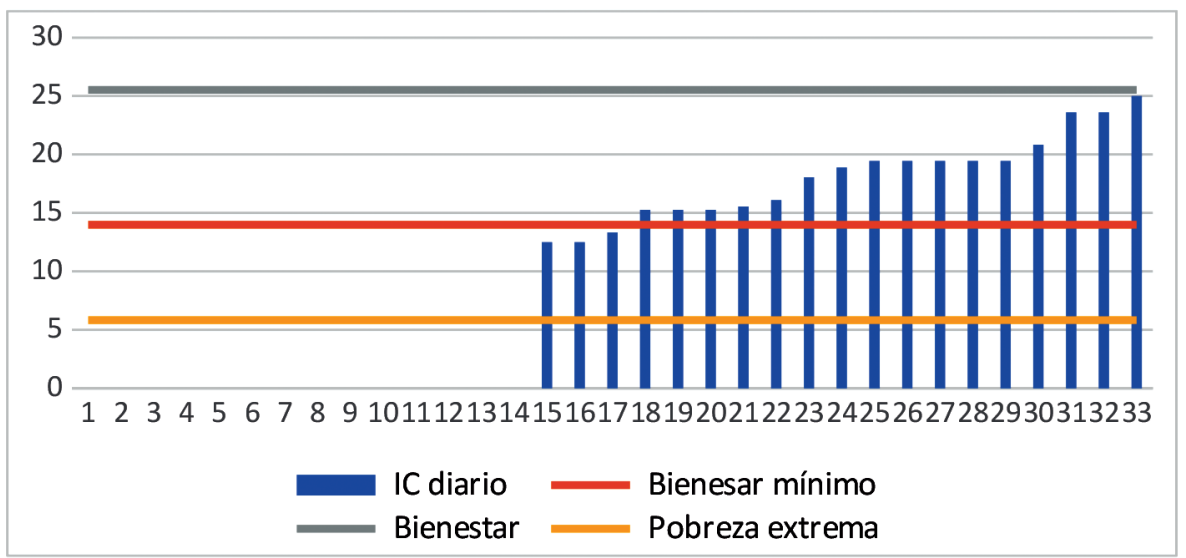

Fuente: Elaboración con datos recolectados en campo.

El gráfico 4 da cuenta de la distribución del ingreso de la muestra por localidad. Esto permite evidenciar que los ingresos más altos, tanto en hombres como en mujeres, se ubican en Felipe Carrillo Puerto y José María Morelos, localidades urbanas que son las cabeceras municipales de sus respectivos municipios. Asimismo, se puede observar en este gráfico la diferencia entre los ingresos de hombres y mujeres es más marcados en José María Morelos, donde se encuentra el dato máximo de ingreso en hombres, y en El Naranjal, que muestra el mínimo.

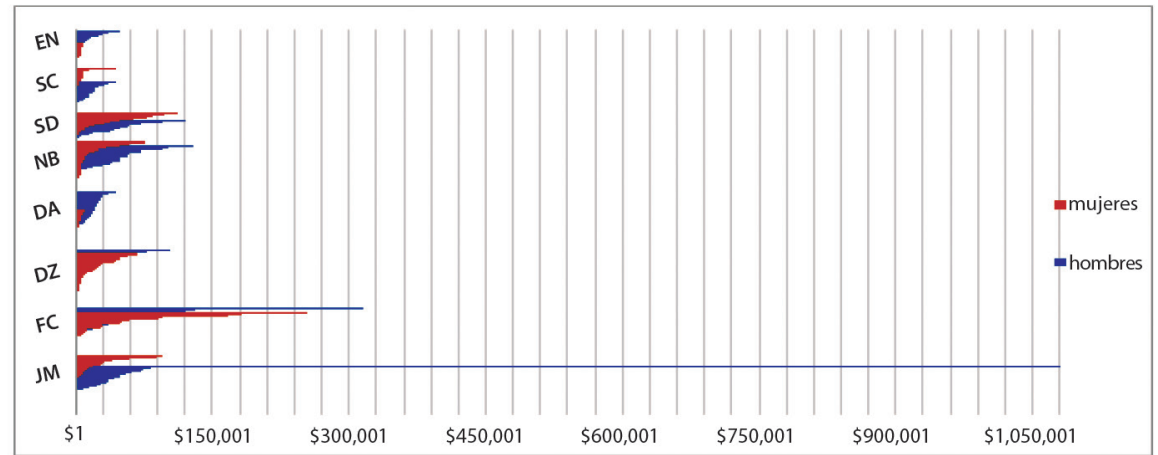

Fuente: Elaboración propia con datos recolectados en campo. 
En el gráfico 5 se observa el ic total de las mujeres por localidad. Al igual que en el gráfico 4, se pone de evidencia que, salvo por Felipe Carrillo Puerto, el resto de las localidades no muestra ingresos tan desiguales entre mujeres, especialmente en aquellas donde los ingresos son bajos como en San Carlos y Dos Aguadas.

\section{INGRESO CORRIENTE DE MUJERES DE LA MUESTRA POR LOCALIDAD 2016}

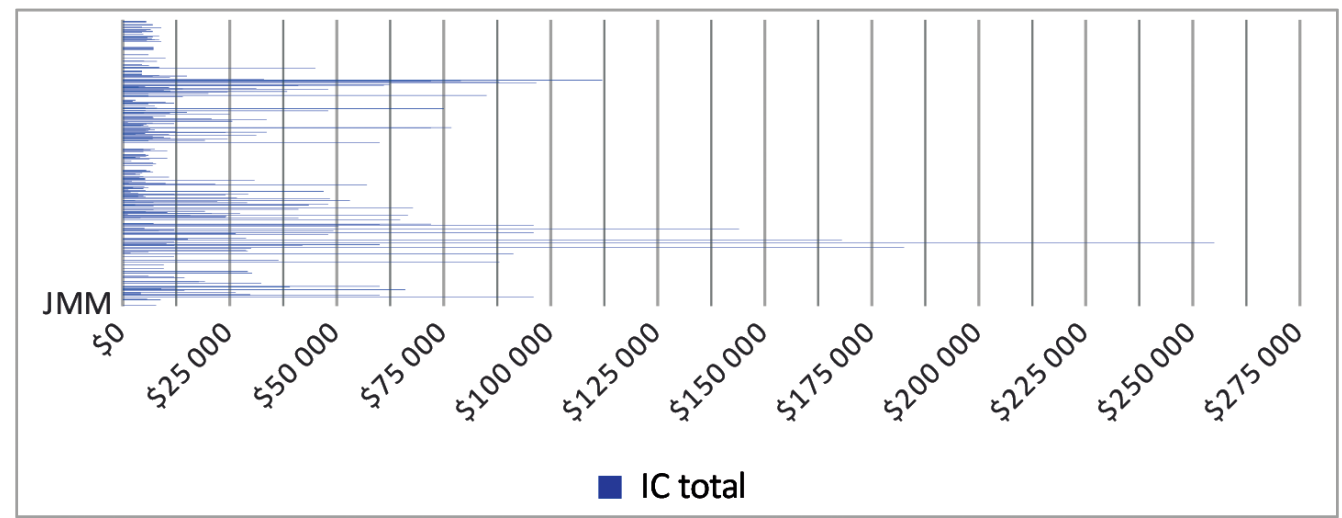

Fuente: Elaboración propia con datos recolectados en campo.

El gráfico 6, perteneciente a la localidad de José María Morelos, muestra que el 63,2\% de las mujeres tienen un Ic igual a cero, lo que automáticamente las coloca por debajo de la línea de pobreza extrema. El 3,9\% reporta ingresos por debajo de la línea de pobreza extrema, lo que deriva en que un $67,1 \%$ del total de mujeres sean las que viven con menos de $\$ 1,25$ dólares americanos al día. Ahora bien, el 9,2\% de las mujeres tiene un ingreso que no rebasa la línea de bienestar mínimo que el CONEVAL establece. Existe un 7,9\% que, si bien, rebasa la línea de bienestar mínimo, no rebasa la línea de bienestar. El 15,8\% de la muestra tiene ingresos por encima de las tres líneas de pobreza que se plantearon, por lo que se les considera no pobres, desde el enfoque del BM y el conEval. 


\section{GRÁFICO 6}

LÍNEAS DE POBREZA

LOCALIDAD JOSÉ MARÍA MORELOS

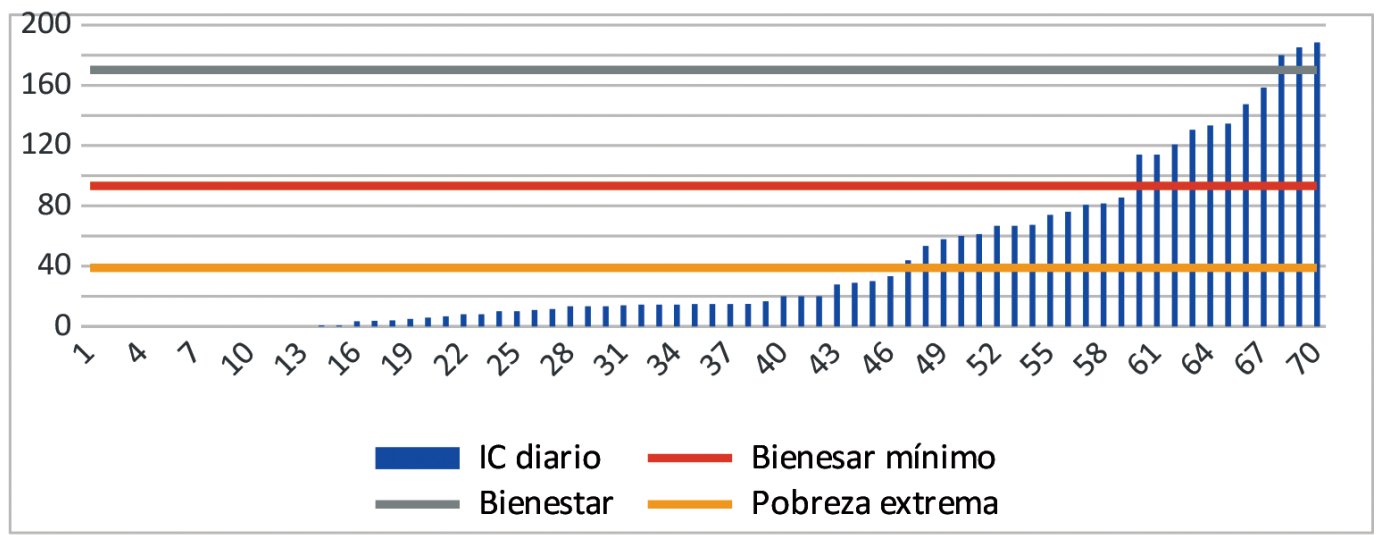

Fuente: Elaboración propia con datos recolectados en campo.

El gráfico 7, perteneciente a la localidad de Felipe Carrillo Puerto, muestra que el $46,4 \%$ de las mujeres tienen un IC igual a cero, lo que las coloca por debajo de la línea de pobreza extrema. El 1,8\% reporta ingresos por debajo de la línea de pobreza extrema, lo que deriva en que un 48,2\% del total de mujeres sean las que viven con menos de $\$ 1,25$ dólares americanos al día. Ahora bien, 8,9\% de las mujeres tiene un ingreso que no rebasa la línea de bienestar mínimo que el CONEval establece. Mientras que existe un $8,9 \%$ que si bien rebasa la línea de bienestar mínimo, no rebasa la línea de bienestar. El 22,2\% de la muestra tiene ingresos por encima de las tres líneas de pobreza que se plantearon en la metodología, por lo que se les considera como no pobres en términos del ingreso.

\section{GRÁFICO 7 \\ LÍNEAS DE POBREZA \\ LOCALIDAD FELIPE CARRILLO PUERTO \\ 2016}

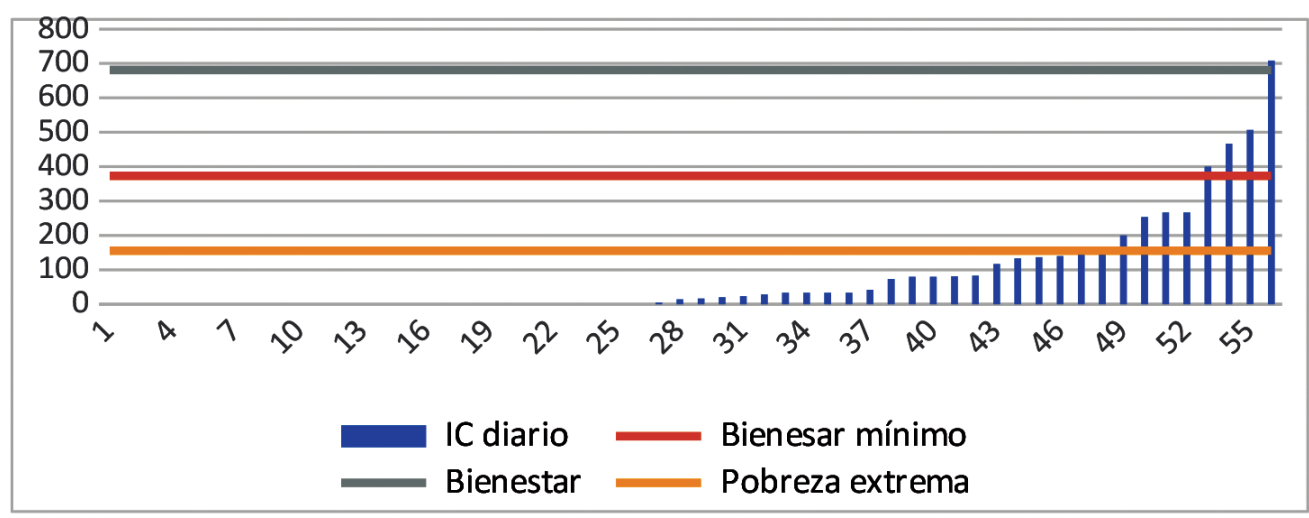

Fuente: Elaboración propia con datos recolectados en campo. 
El gráfico 8, perteneciente a la localidad de Dziuche, muestra que el 18,6\% de las mujeres tienen un ic igual a cero, lo que las coloca por debajo de la línea de pobreza extrema. El 24,3\% reporta ingresos por debajo de la línea de pobreza extrema, lo que deriva en que un $42,9 \%$ del total de mujeres sean las que viven con menos de $\$ 1,25$ dólares americanos al día. Ahora bien, 21,4\% de las mujeres tiene un ingreso que no rebasa la línea de bienestar mínimo que el CONEVAL establece. Mientras que existe un 5,7\% que, si bien, rebasa la línea de bienestar mínimo, no sobrepasa la línea de bienestar. El 30\% de la muestra tiene ingresos por encima de las tres líneas de pobreza que se plantearon en la metodología, por lo que se les considera como no pobres en términos del ingreso.

\section{GRÁFICO 8 \\ LÍNEAS DE POBREZA \\ LOCALIDAD DZIUCHÉ \\ 2016}

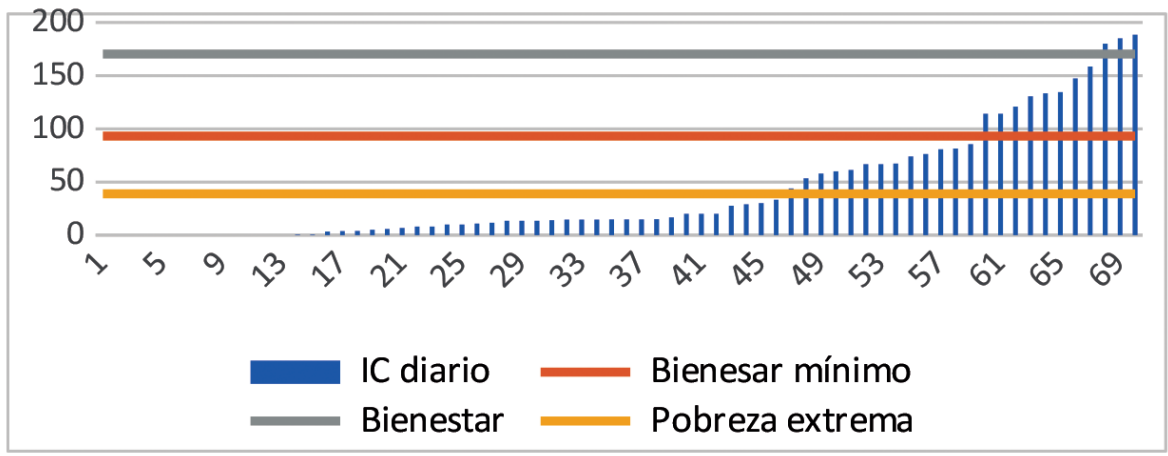

Fuente: Elaboración propia con datos recolectados en campo.

El gráfico 9, perteneciente a la localidad de Dos Aguadas, muestra que el 55,7\% de las mujeres tienen un IC igual a cero, lo que automáticamente las coloca por debajo de la línea de pobreza extrema. El 15,38\% reporta ingresos por debajo de la línea de pobreza extrema, lo que deriva en que un $71,08 \%$ del total de mujeres sean las que viven con menos de $\$ 1,25$ dólares americanos al día. Ahora bien, el resto de las mujeres, $28 \%$, tiene un ingreso que no rebasa la línea de bienestar mínimo que coneval establece, es decir, para el gobierno mexicano, el 100\% de las mujeres de la muestra en Dos Aguadas viven en condiciones de pobreza extrema en términos del ingreso. 

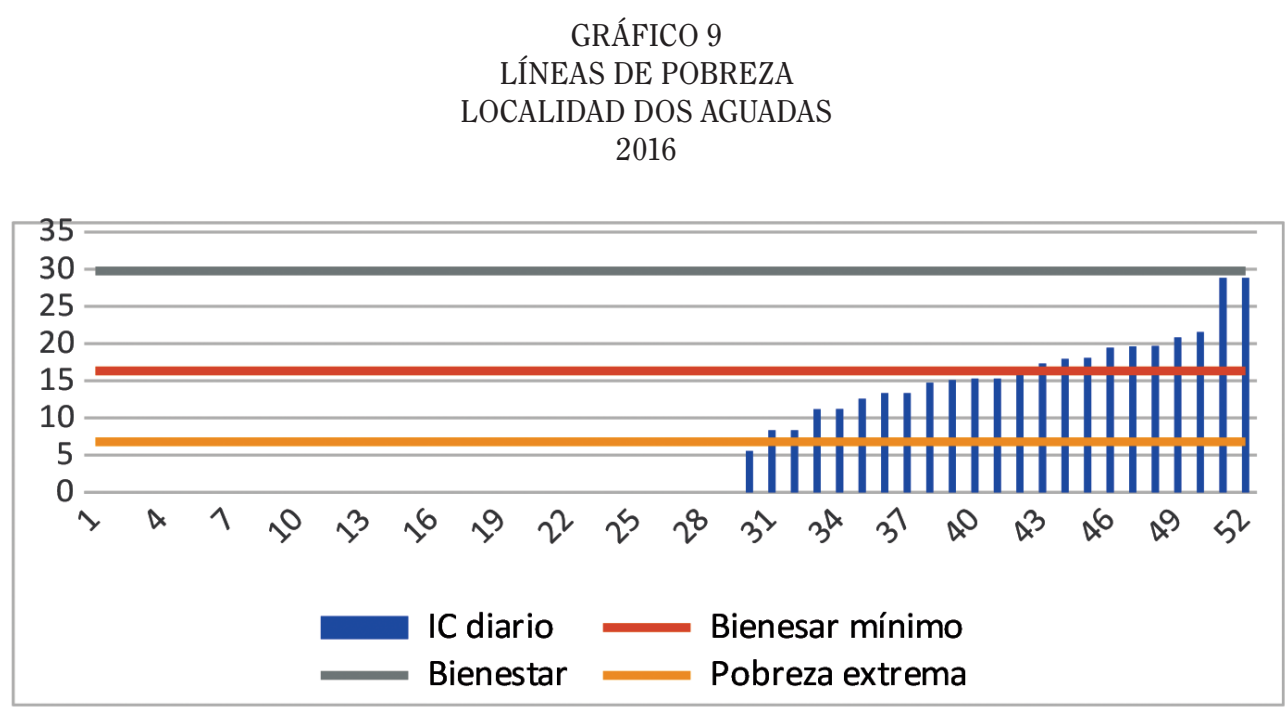

Fuente: Elaboración propia con datos recolectados en campo.

El gráfico 10, perteneciente a la localidad de Noh-Bec, muestra que el 26,1\% de las mujeres tienen un ic igual a cero, lo que las coloca por debajo de la línea de pobreza extrema. El 7,6\% reporta ingresos por debajo de la línea de pobreza extrema, lo que deriva en que un $33,7 \%$ del total de mujeres sean las que viven con menos de $\$ 1,25$ dólares americanos al día. Ahora bien, $38,5 \%$ de las mujeres tiene un ingreso que no rebasa la línea de bienestar mínimo que el conEval establece. Mientras que existe un $9,2 \%$ que, si bien, rebasa la línea de bienestar mínimo, no rebasa la línea de bienestar. El 18,5\% de la muestra tiene ingresos por encima de las tres líneas de pobreza que se plantearon en la metodología, por lo que se les considera como no pobres en términos del ingreso.

GRÁFICO 10

LÍNEAS DE POBREZA

LOCALIDAD NOH BEC

2016

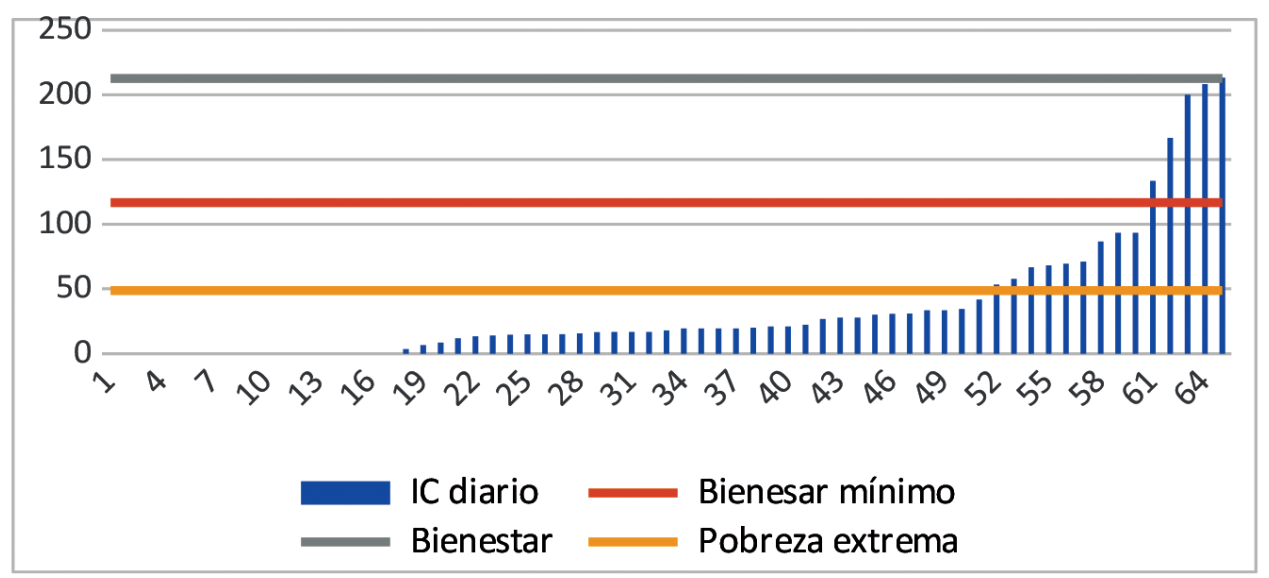

Fuente: Elaboración propia con datos recolectados en campo. 
En el gráfico 11 puede observarse el resultado para la localidad de San Diego, en la que se muestra que el $27 \%$ de las mujeres tienen un ic igual a cero, lo que las coloca por debajo de la línea de pobreza extrema. El $8,1 \%$ reporta ingresos por debajo de la línea de pobreza extrema, lo que deriva en que un $35,1 \%$ del total de mujeres sean las que viven con menos de $\$ 1,25$ dólares americanos al día.
Ahora bien, $18,9 \%$ de las mujeres tiene un ingreso que no rebasa la línea de bienestar mínimo que el CONEVAL establece. Mientras que un $8,1 \%$ que, si bien, rebasa la línea de bienestar mínimo, no rebasa la línea de bienestar. El $37,8 \%$ de la muestra tiene ingresos por encima de las tres líneas de pobreza que se plantearon en la metodología, por lo que se les considera como no pobres en términos del ingreso.
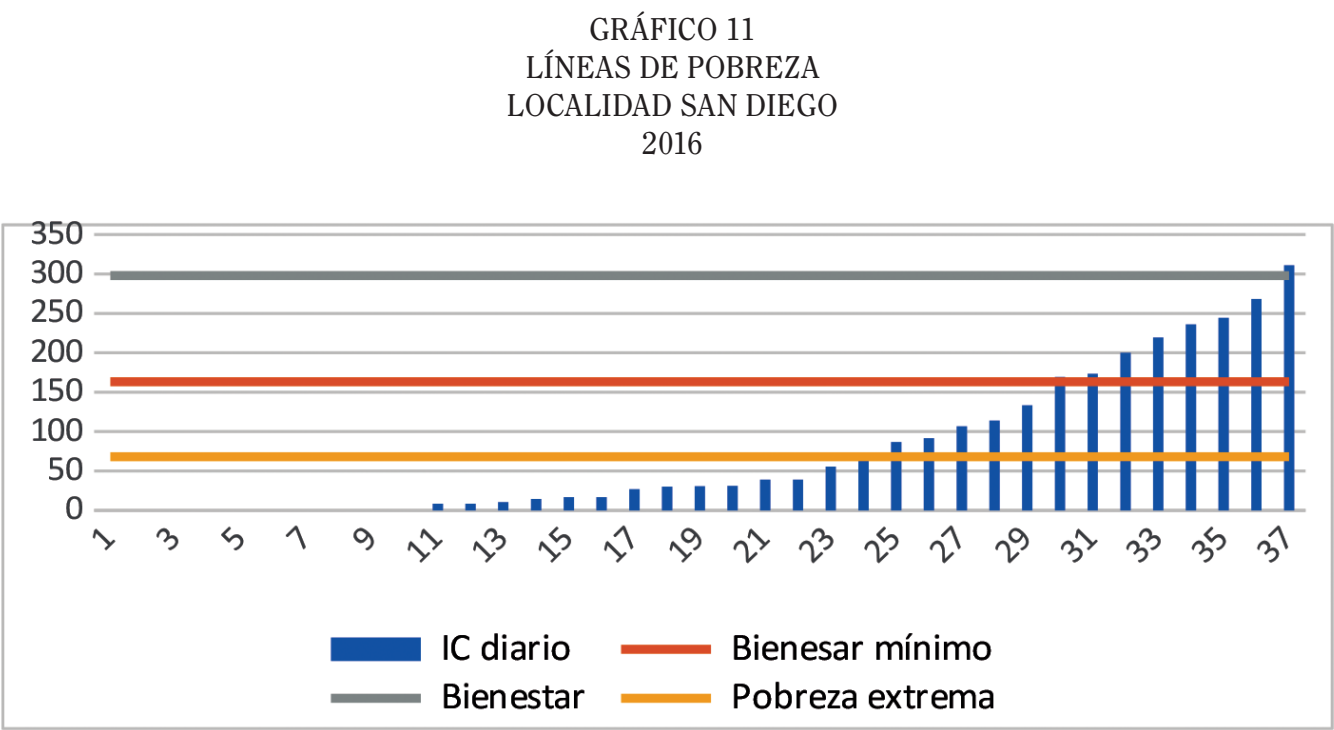

Fuente: Elaboración propia con datos recolectados en campo.

El gráfico 12, perteneciente a la localidad de San Carlos, muestra que el 42,4\% de las mujeres tienen un IC igual a cero, lo que automáticamente las coloca por debajo de la línea de pobreza extrema. El 9,1\% reporta ingresos por debajo de la línea de pobreza extrema, lo que deriva en que un 51,5\% del total de mujeres sean las que viven con menos de $\$ 1,25$ dólares americanos al día. Ahora bien, 48,5\% de las mujeres tiene un ingreso que no rebasa la línea de bienestar mínimo ni la de bienestar que el CONEVAL establece. El 0\% de la muestra tiene ingresos por encima de las tres líneas de pobreza que se plantearon en la metodología. 
GRÁFICO 12

LÍNEAS DE POBREZA SAN CARLOS

2016

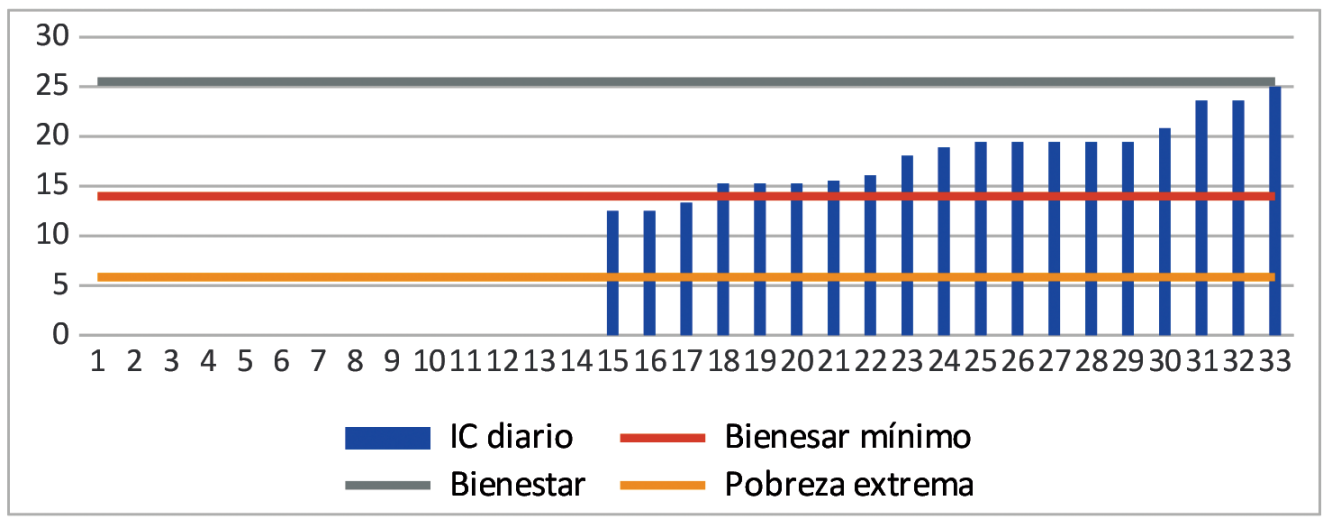

Fuente: Elaboración con datos recolectados en campo.

El gráfico 13, perteneciente a la localidad de El Naranjal, muestra que el $61 \%$ de las mujeres tienen un IC igual a cero, lo que las coloca por debajo de la línea de pobreza extrema. El $10,2 \%$ reporta ingresos por debajo de la línea de pobreza extrema, lo que deriva en que un $71,2 \%$ del total de mujeres sean las que viven con menos de $\$ 1,25$ dólares americanos al día. Ahora bien, 25,4\% de las mujeres tiene un ingreso que no rebasa la línea de bienestar mínimo que el coneval establece. Mientras que existe un solo caso, es decir, 1,7\% que aunque supera la línea de bienestar mínimo, no alcanza a superar la línea de bienestar. Solo una mujer, el $1,7 \%$, de la muestra tiene ingresos por encima de las tres líneas de pobreza que se plantearon en la metodología, por lo que se le considera como no pobre en términos del ingreso.

GRÁFICO 13

LÍNEAS DE POBREZA

LOCALIDAD EL NARANJAL 2016

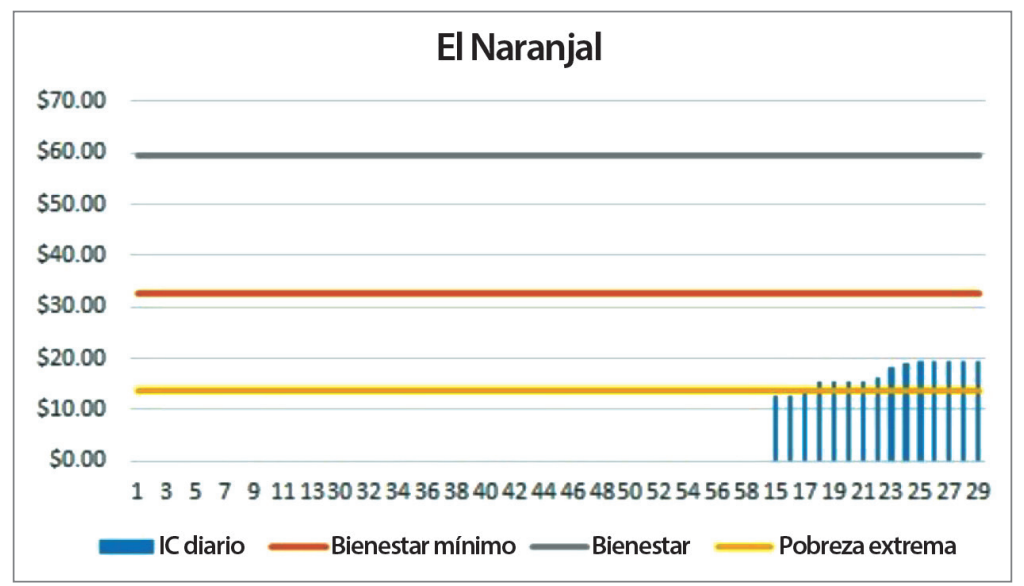

Fuente: Elaboración propia con datos recolectados en campo. 
Los datos numéricos que este documento muestra $y$ discute son poco alentadores. Tal pareciera que 30 años de programas federales de "combate a la pobreza" basados en el desarrollo social no han sido adecuados ni suficientes para las personas beneficiarias, $y$ mucho menos lo han sido para las mujeres de la zona Maya. Basta ver la tabla 3 y 4 para dar cuenta de la afirmación anterior. Según la tabla 4, que es un resumen sobre la situación económica de las mujeres de la muestra bajo la perspectiva del Banco Mundial y del coneval, se puede observar que el porcentaje de mujeres que carece de ingreso alguno en el mejor de los casos es de casi una quinta parte, mientras que en el peor de los escenarios es superior a tres quintas partes.

TABLA 3

CONCENTRADO DE PORCENTAJES DE TIPOS DE INGRESOS EN MUJERES

DE LAS LOCALIDADES DE ESTUDIO

2016

\begin{tabular}{|c|c|c|c|c|c|}
\hline \multirow[b]{2}{*}{ LOCALIDAD } & \multirow[b]{2}{*}{$\begin{array}{c}\text { SIN } \\
\text { INGRESO }\end{array}$} & \multirow{2}{*}{$\begin{array}{c}\text { BANCO MUNDIAL } \\
\text { Mujeres } \\
\text { con ingresos } \\
<\text { línea de pobreza }\end{array}$} & \multicolumn{3}{|c|}{ CONEVAL } \\
\hline & & & $\begin{array}{c}\text { Mujeres } \\
\text { con ingresos } \\
<\text { línea de bienestar } \\
\text { mínimo }\end{array}$ & $\begin{array}{c}\text { Mujeres } \\
\text { con ingresos } \\
<\text { línea de bienestar }\end{array}$ & $\begin{array}{l}\text { Mujeres } \\
\text { No pobres }\end{array}$ \\
\hline José Ma. Morelos & $63,2 \%$ & $3,9 \%$ & $9,2 \%$ & $7,9 \%$ & $15,8 \%$ \\
\hline Felipe C. Puerto & $46,4 \%$ & $1,8 \%$ & $8,9 \%$ & $8,9 \%$ & $33,9 \%$ \\
\hline Dziuché & $18,6 \%$ & $24,3 \%$ & $21,4 \%$ & $5,7 \%$ & $30,0 \%$ \\
\hline Dos Aguadas & $55,8 \%$ & $15,4 \%$ & $28,8 \%$ & $0,0 \%$ & $0,0 \%$ \\
\hline Noh Bec & $26,2 \%$ & $7,7 \%$ & $38,5 \%$ & $9,2 \%$ & $18,5 \%$ \\
\hline San Diego & $27,0 \%$ & $8,1 \%$ & $18,9 \%$ & $8,1 \%$ & $37,8 \%$ \\
\hline San Carlos & $42,4 \%$ & $9,1 \%$ & $48,5 \%$ & $0,0 \%$ & $0,0 \%$ \\
\hline El Naranjal & $61,0 \%$ & $10,2 \%$ & $25,4 \%$ & $1,7 \%$ & $1,7 \%$ \\
\hline
\end{tabular}

Fuente: $\quad$ Elaboración propia con datos recolectados en campo.

Ahora bien, en el gráfico 4 se observa que hay un número significativo de mujeres que, aún con algún tipo de ingreso (sea producto de algún trabajo o ingreso de las Transferencias Monetarias Condicionadas de algún programa de combate a la pobreza), subsisten con menos de $\$ 1,25$ dólares americanos al día, es decir, con menos de $\$ 13,62$ pesos mexicanos. Del mismo modo, se observa en esta tabla que los porcentajes de mujeres que tienen ingresos por encima de la línea de pobreza extrema señalada por el Banco Mundial, pero por debajo de la línea de Bienestar Mínimo del coneval es variado. Por ejemplo, en las dos localidades más urbanizadas es de apenas el 8,9\% y 9,2\%, mientras que en localidades como San Carlos $y$ Dos Aguadas resulta preocupante que en 
esta categoría están la mayoría de los casos, pues no hay datos de mujeres cuyos ingresos superen la línea de Bienestar Mínimo.

En la tabla 4 también se indica el porcentaje tan bajo de mujeres cuyos ingresos están por encima de la línea de Bienestar Mínimo, pero por debajo de la línea de Bienestar, es decir, sus ingresos diarios son mayores a $\$ 32,64$ pesos mexicanos diarios, pero menores a $\$ 59,57$ pesos mexicanos. Y, finalmente, en la tabla 4 , la columna de Mujeres No pobres indica la cantidad de mujeres que son así consideradas por tener ingresos superiores a los marcados por los instrumentos metodológicos, sin embargo, una de las grandes críticas que existen a dichos instrumentos es que si el ingreso es de apenas $\$ 1$ peso mexicano por encima de las líneas, el individuo habrá superado la pobreza. En este caso, solo en las localidades de Felipe Carrillo Puerto y San Diego, la porción de mujeres no pobres es superior a una tercera parte, en el peor de los escenarios están Dos Aguadas y San Carlos donde no hay evidencia de mujeres no pobres y El Naranjal donde el porcentaje es apenas superior del $1 \%$.

En la tabla 5 se observan los acumulados porcentuales de cada situación de línea de pobreza. Por ejemplo, llama la atención que en localidades como Dos Aguadas y San Carlos el $100 \%$ de las mujeres viven con ingresos por debajo de la línea de Bienestar Mínimo del CONEval. Otro caso llamativo es el de El Naranjal, José María Morelos y Noh Bec, localidades en donde el $98 \%$, $84 \%$ y $82 \%$, respectivamente, de las mujeres viven con ingresos diarios inferiores a $\$ 59,57$ pesos mexicanos.

TABLA 4

CONCENTRADO ACUMULADO DE PORCENTAJES DE TIPOS DE INGRESOS EN MUJERES DE LAS LOCALIDADES DE ESTUDIO 2016

\begin{tabular}{|c|c|c|c|c|c|}
\hline \multirow[b]{2}{*}{ LOCALIDAD } & \multirow[b]{2}{*}{$\begin{array}{c}\text { SIN } \\
\text { INGRESO }\end{array}$} & BANCO MUNDIAL & \multicolumn{3}{|c|}{ CONEVAL } \\
\hline & & $\begin{array}{c}\text { Mujeres } \\
\text { con ingresos } \\
<\text { línea de pobreza }\end{array}$ & $\begin{array}{c}\text { Mujeres } \\
\text { con ingresos } \\
<\text { línea de bienestar } \\
\text { mínimo }\end{array}$ & $\begin{array}{c}\text { Mujeres } \\
\text { con ingresos } \\
<\text { línea de bienestar }\end{array}$ & $\begin{array}{c}\text { Mujeres } \\
\text { No pobres* }\end{array}$ \\
\hline José Ma. Morelos & $63 \%$ & $67 \%$ & $71 \%$ & $84 \%$ & $16 \%$ \\
\hline Felipe C. Puerto & $46 \%$ & $48 \%$ & $57 \%$ & $66 \%$ & $34 \%$ \\
\hline Dziuché & $19 \%$ & $43 \%$ & $64 \%$ & $70 \%$ & $30 \%$ \\
\hline Dos Aguadas & $56 \%$ & $71 \%$ & $100 \%$ & - & - \\
\hline Noh Bec & $26 \%$ & $34 \%$ & $72 \%$ & $82 \%$ & $18 \%$ \\
\hline San Diego & $27 \%$ & $35 \%$ & $54 \%$ & $62 \%$ & $38 \%$ \\
\hline San Carlos & $42 \%$ & $52 \%$ & $100 \%$ & - & - \\
\hline El Naranjal & $61 \%$ & $71 \%$ & $97 \%$ & $98 \%$ & $2 \%$ \\
\hline TOTAL & $43 \%$ & $53 \%$ & $76 \%$ & $63 \%$ & $18 \%$ \\
\hline
\end{tabular}

Fuente: Elaboración propia con datos recolectados en campo. 


\section{CONCLUSIONES}

El análisis de este artículo es un esfuerzo académico que representa la realidad sobre la pobreza de una parte de las mujeres indígenas que viven en México, por lo que se puede tomar como referencia en cuanto a la forma en que la pobreza se ha manifestado con las mujeres indígenas Maya. Como se evidenció a lo largo del trabajo, los ingresos de las mujeres son significativamente menores comparados con los de los hombres, además de tener una estructura menos variada y más concentrada en los apoyos gubernamentales a través de los programas sociales focalizados a lo largo de las 3 últimas décadas. Dicha situación económica las vuelve vulnerables tanto al interior como al exterior del tejido familiar, pues se provoca dependencia al ingreso de los varones de sus hogares.

Este trabajo también se ha ocupado de mostrar que las políticas sociales de combate a la pobreza no han sido del todo efectivas. Pues, si bien, han ayudado a disminuir la desigualdad que existe en el Ingreso Corriente entre hombres y mujeres, no han sido efectivas para incidir en la categoría de pobreza o no pobreza, claro está, en zonas indígenas cuya vocación es mayormente rural campesina. Es menester que los tomadores de decisiones públicas y los diseñadores de políticas públicas consideren este tipo de estudios para el rediseño de la política social, pues a todas luces, luego de 30 años de programas de combate a la pobreza, los resultados son escuetos y nada alentadores para las mujeres indígenas de esta zona Maya.

Otra de las conclusiones es que a pesar de que son las mujeres las que reciben la trasferencia monetaria de los programas sociales focalizados como OPORTUNIDADES, POGRESA o PROSPERA, la carga laboral en el hogar aumenta sin tener una percepción monetaria extra por ello, ya que son ellas las que deben llevar a cabo las tareas de corresponsabilidad (acudir a pláticas sobre salud, enviar a los hijos a la escuela, por ejemplo). Asimismo, como se ha mostrado, la transferencia monetaria percibida no es suficiente para cubrir las necesidades básicas de hogares de esta zona, ya que tienen en promedio 4,3 miembros por hogar, lo cual hace difícil satisfacer totalmente las necesidades como alimentación o salud.

Ser mujer, habitar en un contexto rural $y$ pertenecer a un grupo indígena, al menos para la realidad mexicana, este cúmulo de características es garantía para vulnerar las condiciones de calidad de vida de dicho grupo. El desarrollo urbano juega un papel preponderante como escalón que permite enfrentar y, quizá, superar la condición de pobreza; por ejemplo, los ingresos más altos, tanto en hombres como en mujeres, se ubican en Felipe Carrillo Puerto y José María Morelos, localidades urbanas y cabeceras municipales de sus respectivos municipios.

En suma, las mujeres en todas las localidades aquí analizadas subsisten con un ingreso diario de $\$ 1,25$ dólares americanos, lo que se traduce en que la pobreza seguirá heredándose a las próximas generaciones, ya que las transferencias monetarias y los planes en las políticas sociales no son garantía para abatir las condiciones de pobreza, escasez y precariedad. Las mujeres padecen una realidad adversa, $y$ este artículo se ha encargado de evidenciar y discutir, al menos, una parte de las condiciones en que este grupo de la población vive diariamente.

\section{REFERENCIAS}

Banco Interamericano para el Desarrollo. (2017). Así funcionan las transferencias condicionadas. Buenas prácticas a 20 años de implementación. Nueva York: BID.

Banco Mundial. (2001). Informe sobre el desarrollo mundial 2000/2001: Lucha contra la pobreza. Washington D.C.: Banco Mundial.

Banco Mundial. (2004). La pobreza en México: una evaluación de las condiciones, las tendencias y la estrategia del Gobierno. México: Banco Mundial.

Banco Mundial. (2009). Transferencias monetarias condicionadas. Reduciendo la pobreza actual y futura. Washington D.C.: Banco Mundial.

Bello, M. y Rangel, M. (2002). La equidad y la exclusión de los pueblos indígenas $y$ 
afrodescendientes en América Latina y el Caribe. Revista de la CEPAL, 76, 39-54.

Benítez, J., Rioja, L., y Guadarrama, R. (2017). México-Cuba: dos proyectos y un distanciamiento estructural bajo el modelo neoliberal. Colección, (26), 49-90.

Comisión Económica para América Latina y el Caribe. (2012). Observatorio de Igualdad de Género de América Latina y el Caribe. Informe anual 2012. Los bonos en la mira: aporte y carga para las mujeres. Recuperado de https://www.cepal. org/cgibin/getProd.aspxml=/publicaciones/xml/7/49307/P49307.xmlyxsl=/publicaciones/ficha.xslybase $=/$ publicaciones/ top_publicaciones.xsl

Comisión Económica para América Latina y el Caribe (CEPAL). (2013). Los programas de transferencias condicionadas perpetúan el rol de la mujer como cuidadora. Recuperado de https://www.cepal.org/es/ comunicados/los-programas-de-transferencias-condicionadas-perpetuan-el-rolde-la-mujer-como

Comisión Económica para América Latina $y$ el Caribe (CEPAL). (2014). Panorama social de América Latina 2014. Recuperado de https://www.cepal.org/es/ publicaciones/37626-panorama-socialamerica-latina-2014

Comisión Económica para América Latina y el Caribe (CEPAL). (2015). Panorama social de América Latina 2015. Recuperado de https://www.cepal.org/sites/default/files/presentation/files/220321_ps_2015_ppt.pdf

Comisión Económica para América Latina y el Caribe (CEPAL). (2016). Objetivos de desarrollo del milenio en América Latina $y$ el Caribe. Recuperado de https://www. cepal.org/cgi-bin/getprod.asp? xml=/ MDG/noticias/paginas/1/40211/P40211. $\mathrm{xmlyxsl=/MDG/tpl/p18f.xslybase=/MDG/}$ tpl/top-bottom.xsl

Consejo Nacional de Evaluación de la Política de Desarrollo Social. (2010). Metodología para la medición multidimensional de la pobreza en México. México.

Consejo Nacional de Evaluación de la Política de Desarrollo Social. (2016). CONEVAL informa la evolución de la pobreza 2010 2016. Recuperado de http://www.coneval. org.mx/SalaPrensa/Comunicadosprensa/ Documents/Comunicado-09-medicionpobreza-2016.pdf

Cornelius, W., y Myhre, D. (1998). The transformation of rural Mexico: reforming the ejido sector. Los Angeles, Center for Us-Mexican Studies.

Cortés, F.. (2002). Consideraciones sobre la marginalidad, marginación, pobreza y desigualdad en la distribución del ingreso. Papeles de población, 8(31), 9-24.

Cortés, F. (2013). Medio siglo de desigualdad en el ingreso en México. Economía unam, 10 (29), 12-34.

Delgado, J. (1999). La nueva ruralidad en México. Investigaciones geográficas, (39), 82-93.

Instituto Nacional de las Mujeres. (2009). Desagregación de líneas de pobreza para hombres y mujeres. Cuaderno 2. México: Instituto Nacional de las Mujeres.

Escalante, F. (2015). Historia mínima del neoliberalismo. México: El Colegio de la Frontera Norte.

Esquivel, G. (2015). Desigualdad extrema en México. Concentración del poder económico y político. México: oxfaM.

Feres, J., y Mancero, X. (2001). Enfoques para la medición de la pobreza: breve revisión de la literatura. CEPAL.

Gaxiola, A., y Castro, M. (2017). Desigualdad, Turismo y Bienestar: Análisis regional y por estados, según estrato urbano y rural. El Periplo Sustentable, (32).

Gillie, A. (2008). The origin of the poverty line. The Economic History Review, 49 (4), 715-730.

Instituto Nacional de Estadística Geografía e Informática. (2013). Metodología de la Encuesta Nacional de Ingreso y Gasto de los Hogares de México. Recuperado de http://www.inegi.org.mx/est/contenidos/ espanol/metodologias/encuestas/hogares/enigh10_descripcion_bd.pdf

Kay, C. (2009). Estudios rurales en América Latina en el periodo de globalización neoliberal: ¿una nueva ruralidad? Revista mexicana de sociología, 71(4), 607-645. 
Martínez, R., Garmendia, R. y Soto, E. (2012). El Consenso de Washington: la instauración de las políticas neoliberales en América Latina. Política y cultura, (37), 35-64.

ONU Mujeres. (2016). "El progreso de las mujeres en el mundo 2015-2016. Transformar las economías para realizar los derechos". Estudios feministas, 24 (2), 589-614.

Organización de las Naciones Unidas. (2015). Objetivo 10: Reducir inequidades. Recuperado de http://www.mx.undp.org/ content/mexico/es/home/post-2015/sdgoverview/goal-10.html

Organización de las Naciones Unidas. (2000). Objetivos de desarrollo del milenio. Washington, onU.

Ortíz, I. y, Cummins, M. (2012). Desigualdad global: La distribución del ingreso en 141 países. Nueva York: UNICEF.

Ramírez, K., e Ibarra, A. (2015). Percepción local de los servicios ecológicos y de bienestar de la selva de la zona maya en Quintana Roo, México. Investigaciones Geográficas, Boletín del Instituto de Geografía, (86), 67-81.
Rodríguez, C. (2011). Programas de transferencias condicionadas de ingreso e igualdad de género: ¿por dónde anda América Latina? CEPAL: Santiago de Chile.

Sánchez, A. y, Martínez, O. (2016). Capital social y superación de la pobreza urbana: más allá de la política social. Investigium IRE: Ciencias Sociales y Humanas, VII (1), 32-47. Doi: http://dx.doi.org/10.15658/ CESMAG16.05070103

Trivelli, C. (2008). Persistente desigualdad entre indígenas y no indígenas en América Latina. Documento de trabajo/Programa Dinámicas Territoriales Rurales nro. 22. RIMISP-Centro Latinoamericano para el Desarrollo Rural.

Yarrington, T. (2013). Prólogo. En Boltvinik, J. y Damian, A. (Coords). La pobreza en México y el mundo. Realidades y desafíos (pp.7-10). México: Siglo xxI editores.

Fecha de ingreso: 06/03/2018 Fecha de aprobación: 19/11/2018 